\title{
military dentistry:
}




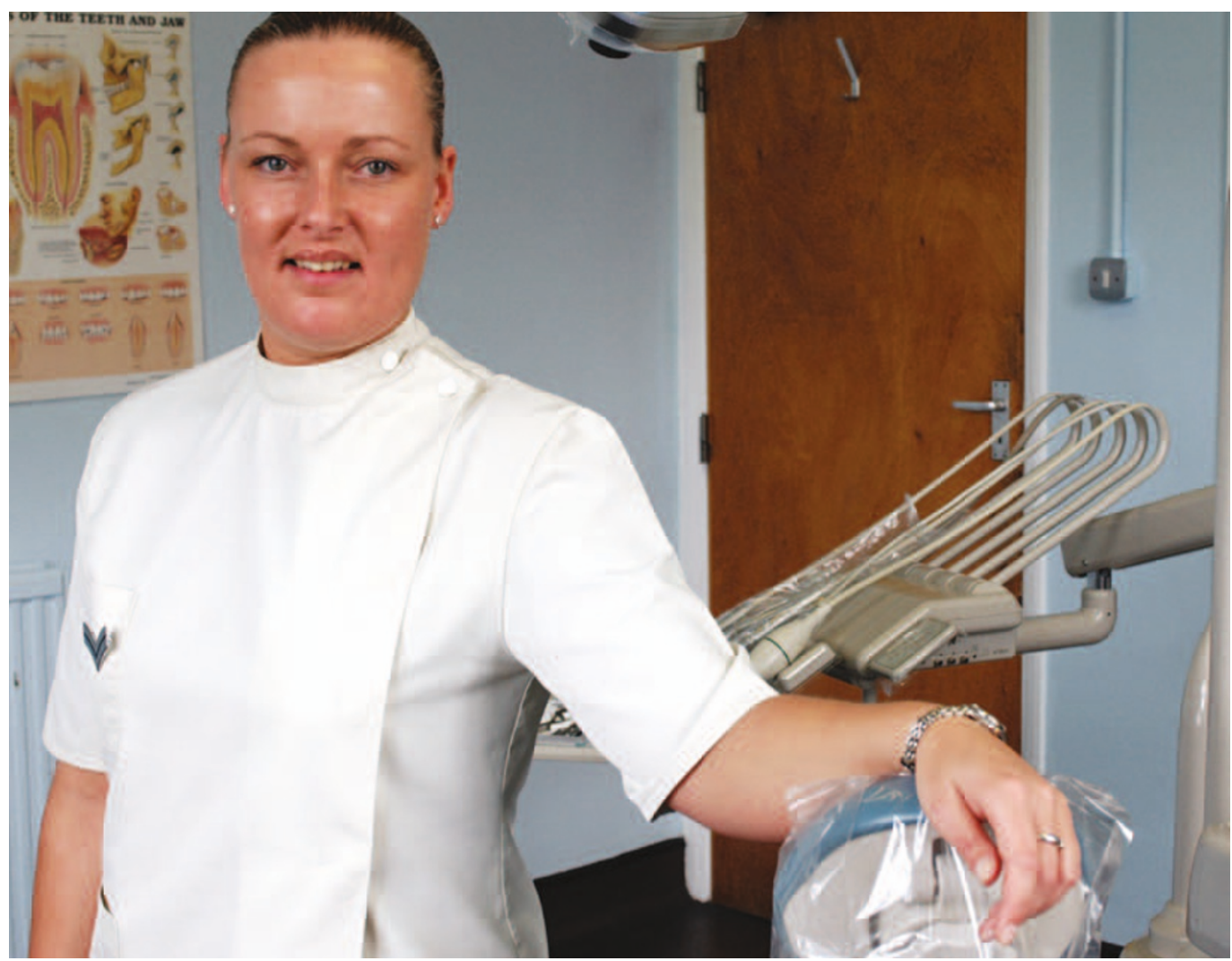

${ }^{6}$ just kept
thinking to
myself that
if I worked

on 'civvy'

street, I

wouldn't

be doing

this!'
Corporal Kerrie Harper (main pic) is a dental support specialist in the Royal Army Dental Corps.

Military life had always appealed to me and I was originally a medical assistant in the Royal Navy for five years. I left for employment in civilian practice in 1996, but felt that I was not pushed to my full potential, so I decided to join the Army. I wanted to stay in a 'caring' profession but didn't want to be a combat medical technician so decided to join the Royal Army Dental Corps as a dental support specialist (DSS). I had never worked in dentistry before, so it was going to be a new and exciting challenge for me.

I had basic training that lasted for 15 weeks, which was hard work but very enjoyable at the same time. I then had to complete the basic DSS training course at Defence Dental Agency Training Headquarters in Aldershot, which lasted 14 weeks.

For my first posting I worked in surgery and initially had a 'mentor' watching over me. Then, after three months, I was asked if I would like the practice manager's job in a new dental centre at the Army Foundation College in Harrogate. I jumped at the chance, it was an excellent opportunity for me and it meant more responsibility and also promotion to the rank of lance corporal. Some of the duties involved being responsible for all dental documentation for a military unit and liaising with military units to ensure that Service personnel were dentally fit to be deployed abroad.

Whilst I was there I did a weeks' adventure training with the Army recruits skiing in North-West Italy. Having never skied before, I just kept thinking to myself that if I worked on 'civvy' street, I wouldn't be doing this!

After leaving Harrogate I went to 39 Engineer Regiment at Waterbeach near Cambridge, where I am currently posted, and though I was still working as a practice manager I was promoted to corporal.

It was another busy dental centre as, in addition, I also had to run the dental centre at 33 Explosive Ordnance Depot (EOD) in Saffron Waldon near Essex. I had only one dental officer, so we worked one week at Waterbeach and one week at Saffron Walden.

The two units are very busy because engineers are needed all over the world and they need to be dentally fit to deploy at short notice. We also provide a dental service to the Army Training Regiment Bassingbourn when they have soldier recruit intakes. I have always worked in busy dental centres but it has always been fun and I wouldn't change it.

When I joined the Army, I wanted to travel and my chance came at long last when in November 2003 I deployed to Iraq with 22
Field Hospital, the British Military Hospital that provided medical and dental support to British and coalition troops. The hospital was tented and had 75 beds and the dental department consisted of two dental officers and two dental nurses, myself being one of them. Personnel were accommodated in tents with eight people to each one. We slept on camp cots, with each tent having lighting and electricity.

There were two chairs operational at Shaibah, using the portable dental unit (PDU). The PDU can sometimes become difficult to maintain because of the climatic conditions, however the dental support services within the field hospital were always on hand to repair them. The lighting failed frequently, often during stages of treatment, causing anxiety to the patient as sometimes we finished treatment by torchlight! There was never a shortage of dentistry for us to do. We never booked in dental inspections or routine treatment as we were always busy with fresh cases, pericoronitis, ulcers and fractured teeth/fillings.

The role of a military dental nurse is an important part of a soldier's well being, as they have to be dentally fit to support operational commitments, and from my experiences, I would say that the employment of dental nurses in the armed forces is certainly different to that in civilian life! 


\section{military dentistry:}

\section{Petty Officer Dean Hunt is a dental hygienist in the Royal Navy.}

I followed my brother into the Royal Navy in 1991 at the age of seventeen after a brief spell as a painter and decorator, not knowing very much about the Royal Navy Dental Service.

I had absolutely no intention of pursuing a career in healthcare and during my first six years of service in the Royal Navy I was a tactical systems operator on Trafalgar Class nuclear submarines. During this period I served on HMS Trenchant and HMS Turbulent, and managed to top up my suntan in various places such as the United States, Hong Kong, Guam and South Korea. However, one of the great benefits of a career in the Royal Navy is the opportunity to retrain whilst still in service. After six years in the submarine service I realised it wasn't for me and I joined the Royal Naval Dental Service as a dental surgery assistant. As you can probably guess submariner to dental surgery assistant is not a normal Navy career path!

In the Armed Forces there are two ways of becoming a military dental hygienist. One route is via direct entry as a qualified dental hygienist with the Diploma in Dental Hygiene, or as a transferee from the dental surgery assistant branch. Transferees undergo an interview procedure to assess their suitability to become a dental hygienist student. Military dental hygiene students undergo their training at The School of Dental Hygiene in Aldershot.

My dental hygienist training at Aldershot was an extremely challenging experience, although unlike my civilian colleagues, military dental hygiene students are paid throughout their training. My two years at Aldershot were life changing because not only did I gain my Diploma in Dental Hygiene, I also met my wife Victoria, who was a Royal Air Force dental hygiene student.

I've now been qualified for three years and I'm currently based in HMS Drake in Plymouth. HMS Drake is part of Her Majesty's Naval Base Devonport, the largest base in Western Europe. My primary role is working in my surgery as a dental hygienist. However, I often find myself carrying out other roles such as practice management, conducting staff training and appraisals, organising adventure training or oral health promotion and acting as duty dental nurse for all the military personnel in the South West.

As a dental hygienist in the Royal Navy

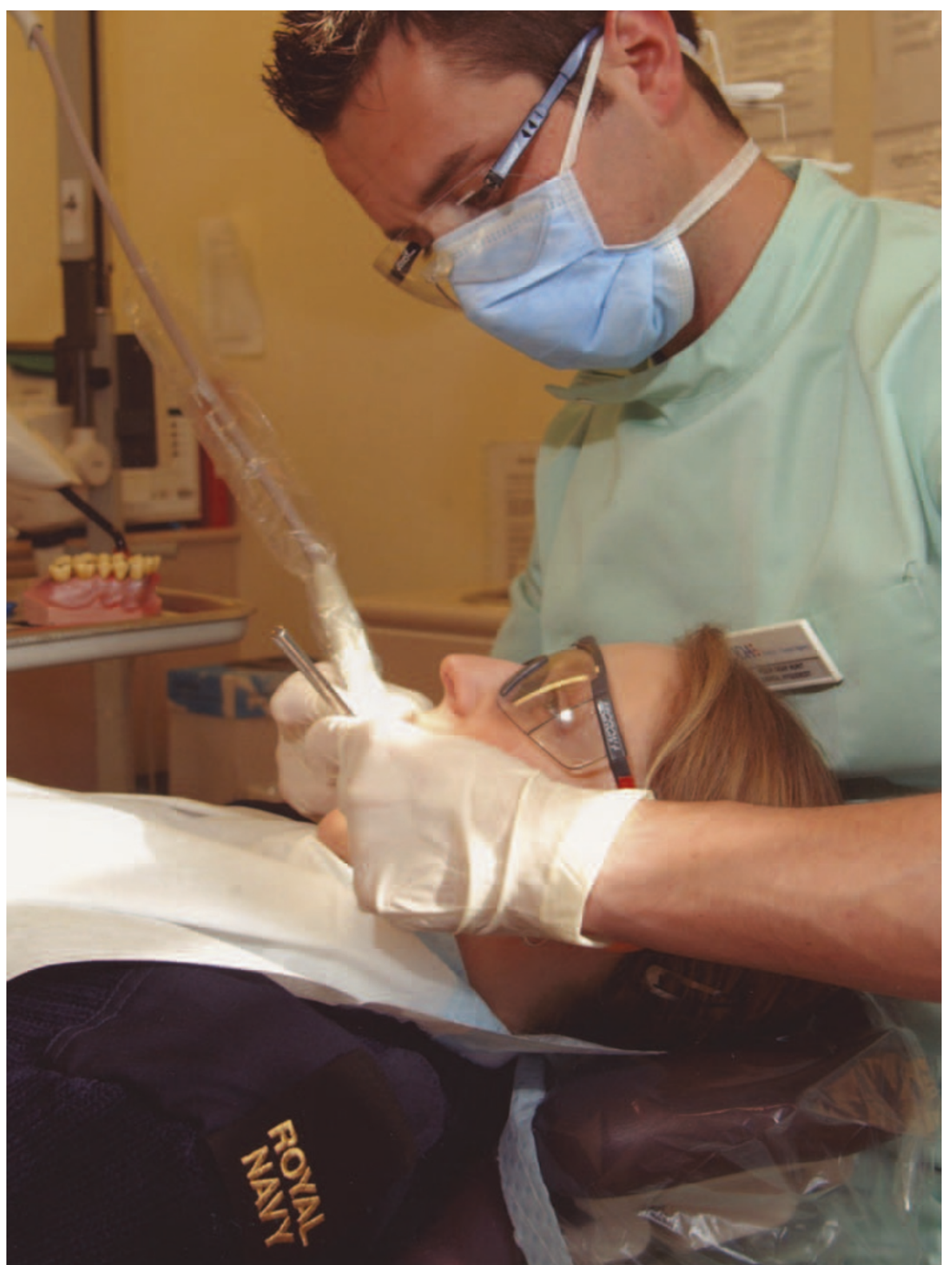

\section{"As a hygienist in the Royal Navy I play an essential role in the oral health care of our service personnel ${ }^{\text {}}$}

you gain promotion according to your performance and ability to pass certain exams. Once these are under your belt you must also pass command courses for each promotion. These courses develop, stretch and test your communication, management - and fitness levels! These courses involve various activities many of which result in being neck-deep in mud, cold or wet, but usually a combination of all three! Activities I've undertaken on these courses include trekking over the Brecon Beacons and
Salisbury Plain, assault courses, disaster exercises and various other team and individual tests. It all sounds a bit grim but with a sense of humour and the feeling of achievement on completion it's worth it, and so is the pay rise! As you achieve promotion in the Royal Navy different jobs become available to you, such as teaching or administrative roles within the training and management of military dental personnel.

As one of the 15 dental hygienists in the Royal Navy I play an essential role in the oral 


\section{military dentistry}

healthcare of our service personnel. Alongside the dental team, we hygienists attempt to reduce the chances of dental morbidity while military personnel are in conflict, on operations, in training and during peacetime.

I've been extremely lucky to have trained as a dental hygienist in the Royal Navy. It has provided an excellent environment in which to train and work. Having a diverse career path, good rates of pay and pension benefits has made my career so far a rewarding and challenging experience.

\section{'As a civilian}

\section{dental}

technician, I doubt whether I

would have

experienced the

same excitement

and diversity.

\section{Warrant Officer Rob Lawson is a dental technician in the Royal Air Force.}

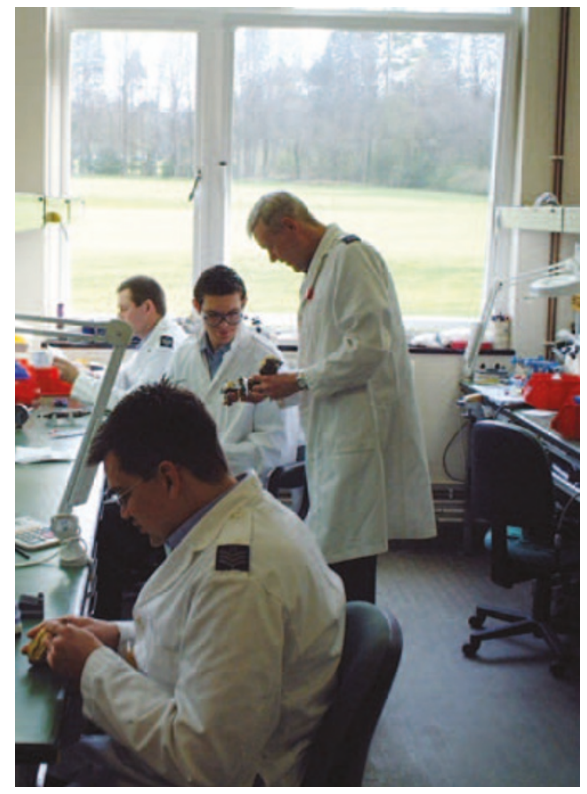

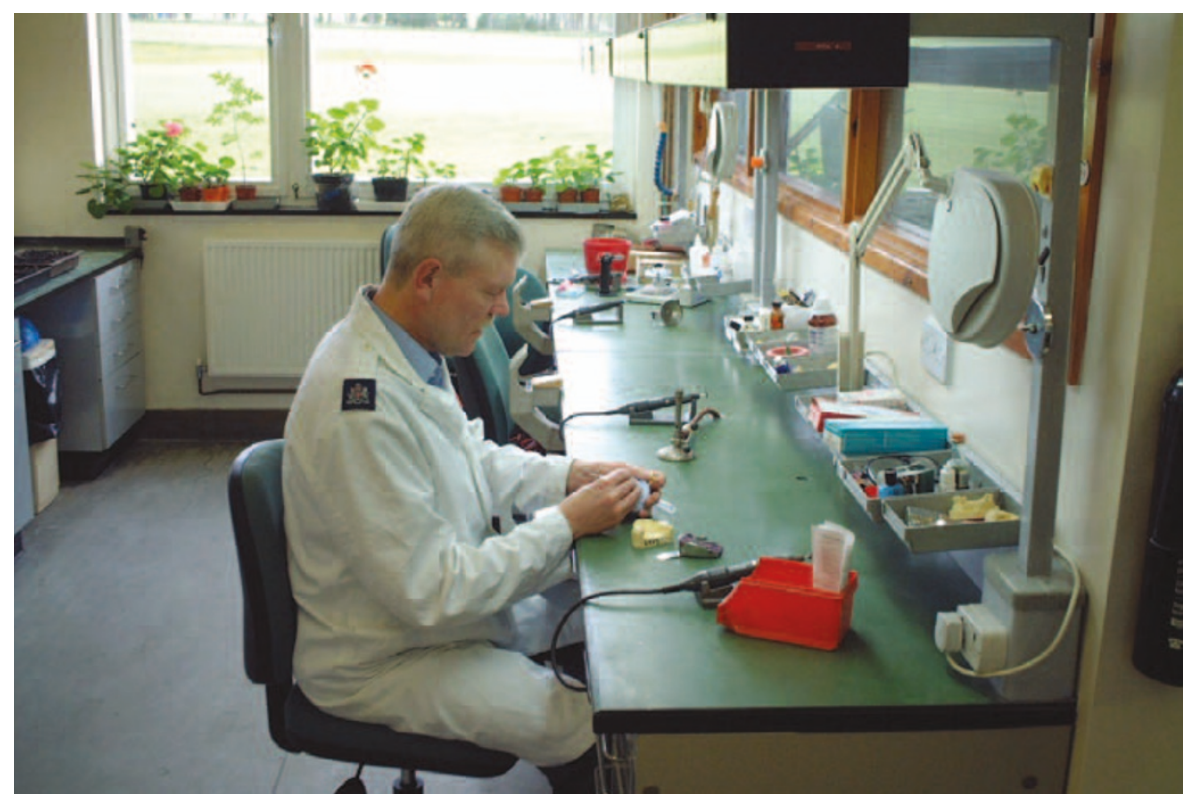

After leaving school in the mid 1970s, I began a dental technician apprenticeship working at a small local dental laboratory. I qualified in 1978, finishing my apprenticeship in 1979 and continued working at the same laboratory until I noticed a magazine advertisement inviting young, qualified dental technicians to apply to join the Royal Air Force (RAF). Joining the RAF was something that I had contemplated doing since my early teens but had never actually got around to doing anything about. I was hooked; this seemed like the ideal opportunity, doing the job which I had grown to like, whilst at the same time seeing the world and experiencing something different.

When I had my basic training along with my fellow recruits, I soon came to terms with my new environment. The training was hard but the level of camaraderie was something I had never experienced before, friendships were forged in those first few weeks which were to last for a life-time.

After this I was taken back to a more familiar environment albeit a military one when I was posted to the Central Dental Laboratory at RAF Halton in Buckinghamshire. After all, a dental laboratory is still a dental laboratory wherever it is situated.

The first thing that struck me, after working in the commercial world for seven years, was the general high standard of dentistry within the Service. I had always taken pride in the work I produced and it pleased me to think that I was now working for an organisation with the same ethos.

Over the next 20 years I worked in a variety of roles mixing dental technology with military duties. Clinically I have undertaken train- ing in maxillofacial work, advanced crown and bridge techniques, advanced prosthetics and orthodontics. Outside of the laboratory my military duties include weapons training and physical fitness training.

Having worked in close support to oral surgeons at maxillofacial units and also to clinical advisors in prosthetics and conservative dentistry, my technical experience has increased greatly over the years, enabling me to become a trainer myself. I have now become more involved with laboratory management and the total provision of technical services to the Defence Dental Agency, I currently oversee up to nine military labs. Ironically I am now posted to RAF Halton, which was my first posting in 1981 albeit now in a very different role.

As serving members of Her Majesty's Armed Forces, dental professionals employed within the Defence Dental Agency are expected to undertake their share of military activities. I was involved on a medical level during the first Gulf conflict and have undertaken operational commitments in both Iraq and Afghanistan throughout the last year.

Whilst these are not the most pleasant aspects of the job, I don't regret joining the RAF as a dental technician for one minute. As a civilian dental technician, I doubt whether I would have experienced the same excitement and diversity while at the same time allowing me to continue and develop my skills in my chosen profession.

For details about a career in the military as a dental professional email Captain Paul Leightonondda-ppcc@defence.mod.uk. 